\title{
Optimal taxation under a consumption target
}

\author{
Junichi Minagawa1 ${ }^{1}$ Thorsten Upmann ${ }^{2,3,4}$
}

Received: 29 November 2016 / Accepted: 7 December 2017 / Published online: 14 December 2017 (C) Springer-Verlag GmbH Germany, part of Springer Nature 2017

\begin{abstract}
While in the familiar problem of optimal commodity taxation the government faces a constraint on tax revenue, we consider the case of a consumption target on a group of commodities (i.e., a weak constraint on total consumption), instead. This optimal commodity tax problem with a consumption target brings about taxation rules that are mainly at variance with the standard results of commodity taxation. In our main theorem, we derive a general, though quite simple, rule of optimal commodity taxation under a target on total consumption: in particular, we establish that higher consumer prices should be charged for commodities with (1) high price elasticities of total demand and (2) low consumption shares in total demand. From this theorem we deduce three important corollaries: an anti-inverse elasticity result, an anti-CorlettHague result and a uniform-pricing result. All of these results are (generically) at variance with well-known rules of commodity taxation.
\end{abstract}

$凶 \quad$ Junichi Minagawa

minagawa@tamacc.chuo-u.ac.jp

Thorsten Upmann

Thorsten.Upmann@hifmb.de

1 Faculty of Economics, Chuo University, 742-1 Higashinakano, Hachioji, Tokyo 192-0393, Japan

2 Helmholtz-Institute for Functional Marine Biodiversity at the Oldenburg University (HIFMB), Ammerländer Heerstraße 231, 23129 Oldenburg, Germany

3 Faculty of Business Administration and Economics, Bielefeld University, Bielefeld, Germany

4 CESifo, Munich, Germany 


\section{Introduction}

The problem addressed in this paper is how a government facing a predetermined consumption target for a group of commodities should set price-based instruments such as taxes (or subsidies). Governments frequently face quantity targets, due to either environmental or social reasons. For example, we may consider the target level for some pollutant to protect the environment; or we may think of merit and demerit goods where the government aims at meeting some specified (minimum respectively maximum) level of consumption. Here, goods such as inoculation against a contagious disease, education, cultural goods, sporting activities and safety precaution may represent examples for the first category; and cigarettes, alcohol, drugs, prostitution, and fuel consumption, for the second. ${ }^{1}$ Also, in view of scarce natural resources, the quantity target may represent the sustainable yield of a renewable resource such as fish, game, timber, etc. Finally, in both trade theory and policy quantity targets are not unusual. For example, import quotas for some classes of goods are imposed to protect domestic industries or to discriminate against a foreign country; and for similar reasons, voluntary export restrains may be applied. In all of these cases a government may consider applying familiar fiscal instruments-taxes and subsidies imposed on these goods - to interfere with total consumption. ${ }^{2}$

Frequently, though, governments do not pursue their own objectives rigorously, but compromise to some extent. In particular, governments often announce consumption targets (e.g., on the reduction of environmentally harmful consumption) to be met in the future, but then allow for some degree of deviation from those. To accommodate for this observed behaviour, we formulate a model where non-compliance with the consumption target is possible but is associated with some cost that is increasing and convex in the degree of non-compliance.

Then, the problem of the government may be formulated as choosing consumer prices for the different commodities to maximise consumer welfare minus the deviation cost of missing the target consumption level. We assume that the target consumption level is exogenous: it may be determined by either some political process (e.g., an international environmental agreement), or by institutional constraints (constitutional rights or laws protecting the environment), or it may represent the solution of some more general optimisation problem (welfare maximisation). The particular source of the target, though, is inessential here, and in this sense, our paper contributes to second-

\footnotetext{
${ }^{1}$ For example, since 2003 the WHO requests member states to increase influenza vaccination coverage of all people at high risk with the goal of attaining vaccination coverage of the elderly population of $75 \%$ by 2010 (56th WHA 2003). In 2009 the Council of the EU recommended member states to reach this goal by the winter of 2014/2015 (European Commission 2009). As a second example consider the governmental objective to reduce consumption of alcohol: in 2010 the Russian government, alarmed by Russians' excessive alcohol consumption, pledged to reduce alcohol consumption by 55\% by 2020.

2 For instance, Article 6 of the WHO Framework Convention on Tobacco Control (FCTC, 2003-2005) states “..., each Party should take account of its national health objectives concerning tobacco control and adopt or maintain, as appropriate, measures which may include: (a) implementing tax policies and, where appropriate, price policies, on tobacco products so as to contribute to the health objectives aimed at reducing tobacco consumption." Similarly, environmental taxes are frequently employed to meet predetermined emission or consumption targets. Notable examples are taxes on different types of fuel to accomplish specified $\mathrm{CO}_{2}-$ or $\mathrm{NO}_{\mathrm{X}}$-emission levels.
} 
best taxation: we derive the optimal consumer prices, viz. optimal consumption taxes, under a given consumption target, which itself may or may not be socially optimal.

It may be helpful to think of the target level as the total consumption of a group of commodities generating an externality. To be specific, the target level may be seen as the maximum amount of the emissions of a specified pollutant, such as $\mathrm{CO}_{2}$ or $\mathrm{NO}_{\mathrm{x}}$. Actually, many countries deploy environmental taxes to limit pollutant emissions from transport, taxing different types of fuel, such as gasoline, diesel, etc., at different rates, although the consumption of any of them results in the emission of the same pollutant, e.g., $\mathrm{CO}_{2}$. (This observation still holds true even if we calculate tax rates on the basis of their carbon content.) ${ }^{3}$ It is thus apparent that different commodities of fuel (or more precisely, carbon contained in different types of fuel) may be, and actually are taxed at different rates, while the political interest focuses on total consumption, e.g., on total $\mathrm{CO}_{2}$ emissions, rather than on its composition.

Yet, we do not restrict ourselves to the case of externalities. Rather, as mentioned above, we allow for a broad interpretation of the predetermined target for the total consumption of a group of commodities. Accordingly, we explore the fundamental fiscal problem in a general setting: given the target level of total consumption, how should taxes on different commodities be determined in order to accomplish that target at lowest cost (or highest utility)? This approach is parallel to, though still different from, the standard problem in the optimal taxation literature, where the utility maximisation is subject to a constraint on tax revenue. Since the (weak) constraint ${ }^{4}$ we consider here is on consumption, rather than on tax revenue, we thus explore how the presence of such a quantity constraint affects the existing results of the optimal taxation literature obtained under a revenue constraint. To our knowledge, the role of this type of a constraint has not yet been explored in the literature since the seminal work of Ramsey (1927), whose contribution has recently been thoroughly reviewed and re-evaluated by Stiglitz (2015). Yet, the apparently unnoticed issue of a (weak) quantity constraint is too important to be neglected from a practical point of view as explained above, and also from a theoretical point of view since this modification has unconventional implications as we will demonstrate.

For the standard problem in public finance-utility maximisation subject to a revenue constraint - the literature has established a series of fundamental and well-known results. Among them, the following are the most notable. The inverse elasticity rule (initiated by Ramsey 1927): higher tax rates should be imposed on goods with a less elastic demand. ${ }^{5}$ The Corlett-Hague rule (originating with Corlett and Hague 1953): higher tax rates should be imposed on goods with a lower compensated price elasticity

\footnotetext{
3 Actual tax rates on different types of fuel (and also on energy products and electricity) in the EU are documented by the European Commission (2015). Using these figures it is simple to calculate prices of carbon contained in a specific type of fuel by using the fact that, for example, each gallon of petrol contains $2421 \mathrm{~g}$ of carbon; and each gallon of diesel, $2778 \mathrm{~g}$ (U.S. Environmental Protection Agency 2005).

4 The quantity constraint is weak in the sense that it is not strictly binding, but may be violated provided that the decision maker is willing to carry the associated cost of missing the target.

5 The inverse elasticity rule has two versions, one for compensated demand and one for ordinary demand. See, e.g., Sandmo (1987).
} 
of demand with respect to the price of an untaxed good (e.g., leisure). ${ }^{6}$ Uniform taxation (presented in Diamond and Mirrlees 1971; Sandmo 1974; Sadka 1977): the same tax rates should be imposed on goods if, and only if, the compensated price elasticities of the goods with respect to the price of an untaxed good are all equal. ${ }^{7}$

In this paper, we derive an optimal taxation rule when the government is constrained by a target on the total consumption of a group of commodities. From this general formula, we infer that higher consumer prices should be charged for commodities with high price elasticities for the total demand and for commodities with low consumption shares. Intuitively, this means that higher prices should be charged for those commodities whose prices induce large changes on the total demand (of all commodities). In this way, the government takes advantage of the fact that comparatively small tax rates may suffice to achieve the stipulated consumption target, and thus price distortions are kept to a minimum. We then utilise our general taxation rule to deduce three specific results, all of which are (generically) at variance with familiar rules of taxation. In particular, we first derive an anti-inverse elasticity rule: higher consumer prices should be charged for the commodities with a more elastic demand; and next, an anti-CorlettHague rule: higher consumer prices should be charged for the commodities with the higher compensated price elasticity with respect to an untaxed good. Both, the antiinverse elasticity rule and the anti-Corlett-Hague rule, counter traditional belief and seem to be counter-intuitive in the first instance-but they are actually not: In order for the same reduction in consumption to be accomplished, elastic demand requires a smaller price increase than does inelastic demand, and therefore it is less costly (in terms of reduced consumer surplus) to reduce the consumption of a commodity with elastic rather than with inelastic demand. For this reason, it is more efficient to meet a given target level of total consumption by taxing commodities with higher demand elasticity more heavily than those with less elastic demand. In this way, the target level can be accomplished by bringing forth rather small price distortions. This reasoning applies irrespective of whether the target level has to be reached from above (reduction of demand) or from below (increase of demand).

These results may also be compared with the familiar rules of optimal Pigouvian taxation, when the consumption of a good, or its commodities, generates an externality. For example, Sandmo (1975) considered such an optimal taxation problem under a revenue constraint, and showed that the optimal tax rate of the externality-generating good is a weighted average of its inverse price elasticity of demand and its marginal social damage; moreover, the marginal social damage of the externality-generating good enters the tax formula for that good in an additive way, while it does not enter the tax formulas of all other goods. ${ }^{8}$ For this reason, Sandmo's result may be regarded as a

\footnotetext{
${ }^{6}$ For recent studies of this rule, see Kaplow (2010), who reconsidered the discussion of the rule in the presence of an income tax in the literature, and Kleven et al. (2000), who showed a modified Corlett-Hague rule for optimal taxation with household production.

7 Deaton (1979), Besley and Jewitt (1995), and Barbie and Hermeling (2009) provided conditions on preferences for uniform commodity taxes to be optimal. In particular, these authors showed that uniform commodity taxes are optimal if, and only if, preferences are implicitly (or quasi) separable between leisure and consumption goods.

8 This additive property is a general feature of optimal taxation problems with externalities (see, e.g., Kopczuk 2003).
} 
generalised (or augmented) inverse elasticity result. In view of this characterisation, a comparison of Sandmo's results with the taxation rules derived here-in a model where a possible environmental damage is incorporated as a quantity target on consumptionbrings about the following observations: In both models, the tax rates are proportional to the marginal damage associated with consumption. However, while in Sandmo's taxation rule the tax rates are inversely related to the relevant elasticities of demand, the tax rates are directly related to those elasticities in our model, i.e., under a (weak) quantity constraint. Also, the additive structure of Sandmo's tax formulae-distortion plus marginal damage - does not survive in our model: here the tax rates are the product of the demand elasticity and the marginal damage. Consequently, optimal taxation under a (fiscal) revenue constraint and under a quantity target on consumption (i.e., a weak quantity constraint) bring about quite opposing taxation rules.

Beyond these differences in the formulae of optimal commodity taxation, it is worthwhile to emphasise that the problem we consider here is also conceptually different from the standard optimal Pigouvian taxation problem: We are not interested in a way to internalise consumption externalities, but rather seek the most efficient way to control the total consumption of commodities generating an externality. In particular, we do not (explicitly) assume the presence of externalities in consumption but model the deviation cost of missing a predetermined target consumption level. This approach has practical relevance (especially in the example of $\mathrm{CO}_{2}$ emissions where a government aims to reduce total $\mathrm{CO}_{2}$ emissions) as illustrated above, but, to our knowledge, it has not been studied in the literature.

Finally, we also demonstrate that the solution of the optimal taxation problem under a quantity target yields a (generalised) uniform-pricing result. This result is seemingly in parallel with the well-known rule of uniform taxation: charging the same (weighted) consumer price for all commodities is a solution if, and only if, the compensated price elasticities of the commodities with respect to an untaxed good are all equal. However, even though both results are obtained under the same elasticity condition, the uniformpricing result is at variance with the uniform taxation rule, unless all net prices are equal: the uniform taxation rule implies that higher taxes should be imposed on goods with higher net prices, while the uniform-pricing result implies that higher taxes should be imposed on commodities with lower net prices (provided that taxes are positive). In this sense, the uniform-pricing result may be referred to as an anti-uniform taxation rule.

The fundamental reason that leads to these opposing taxation rules is the tax base effect: any increase (decrease) in a tax rate causes an erosion (broadening) of the tax base. While this reduction (enlargement) of the tax base is an unwelcome effect if the government aims to collect (return) a given amount of public revenue at minimal social cost, it is not only a welcome effect, but precisely the objective of the government to reduce (increase) consumption if a consumption target has to be reached from above (below). Thus, the reversal of the taxation rules mirrors the opposing objectives: nondistortionary taxation versus demand-directing taxation.

In view of these findings, we may conclude the following: (1) the type of the constraint for the optimal commodity taxation problem, a revenue constraint vs. a quantity target, is crucial for the results and thus for policy implications; and (2) 
an accurate estimation of elasticities is crucial for practically determining tax rates optimally.

The rest of this paper is organised as follows. In Sect. 2 we set up the problem of the optimal commodity tax under a consumption target. This problem is then solved in Sect. 3, where we also derive its policy implications. Finally, we conclude in Sect. 4.

\section{Model}

Assume that there are $n$ commodities of a specific group, the (generic) quantities of which we denote by $\mathbf{x}:=\left(x_{1}, x_{2}, \ldots, x_{n}\right) \in \mathbb{R}_{+}^{n}$; and let $\mathbf{p}:=\left(p_{1}, p_{2}, \ldots, p_{n}\right) \in \mathbb{R}_{+}^{n}$ be the corresponding net prices, which we assume to be fixed throughout. Suppose that the set of these commodities is subject to unit taxes, denoted by $\mathbf{t}:=\left(t_{1}, t_{2}, \ldots, t_{n}\right) \in$ $\mathbb{R}^{n}$, so that the consumer prices are given by $\mathbf{q}:=\left(q_{1}, q_{2}, \ldots, q_{n}\right) \in \mathbb{R}_{++}^{n}$ where $\mathbf{q} \equiv \mathbf{p}+\mathbf{t}$. Let $x_{0} \geqq 0$ denote the (generic) quantity of a composite good, which is not subject to taxation, so that its price is simply denoted by $q_{0}>0$.

Suppose that a consumer's preference relation is represented by a continuous utility function $u: \mathbb{R}_{+}^{n+1} \rightarrow \mathbb{R}:\left(x_{0}, \mathbf{x}\right) \mapsto u\left(x_{0}, \mathbf{x}\right)$, which is strictly increasing and strictly quasi-concave on $\mathbb{R}_{++}^{n+1}$, with $u\left(x_{0}, \mathbf{x}\right)=c$ for any $\left(x_{0}, \mathbf{x}\right) \in \mathbb{R}_{+}^{n+1} \backslash \mathbb{R}_{++}^{n+1}$, for some $c \in \mathbb{R}$. The consumer chooses consumption of the $n$ commodities and of the composite good to maximise their utility $u\left(x_{0}, \mathbf{x}\right)$ subject to their budget constraint $\sum_{i=0}^{n} q_{i} x_{i} \leqq I$ where $I>0$ represents the consumer's income. This utility maximisation problem yields ordinary (or Marshallian) demand functions, $x_{0}^{m}\left(q_{0}, \mathbf{q}, I\right)$ and $\mathbf{x}^{m}\left(q_{0}, \mathbf{q}, I\right)$ along with the resulting indirect utility function $V\left(q_{0}, \mathbf{q}, I\right) \equiv u\left(x_{0}^{m}\left(q_{0}, \mathbf{q}, I\right)\right.$, $\left.\mathbf{x}^{m}\left(q_{0}, \mathbf{q}, I\right)\right)$. Correspondingly, the expenditure minimisation problem gives compensated (or Hicksian) demand functions, $x_{0}^{h}\left(q_{0}, \mathbf{q}, v\right)$ and $\mathbf{x}^{h}\left(q_{0}, \mathbf{q}, v\right)$, where $v$ represents a specified utility level.

The government chooses consumer prices $\mathbf{q}$ (or unit taxes $\mathbf{t}$ ) to maximise the welfare, given by the indirect utility $V\left(q_{0}, \mathbf{q}, I\right)$ minus a cost (or damage), $D(Y)$, where $D: \mathbb{R}_{+} \rightarrow \mathbb{R}_{+}$is continuous, increasing and convex, with $D(0)=0$, and $Y \equiv X-\bar{Z}$ denotes the deviation of total consumption $X$ of the $n$ commodities from the specified target amount of total consumption $\bar{Z}$. The consumption target $\bar{Z}$ is assumed to be positive and finite. This cost function allows for some slackness in the achievement of the consumption target, but missing the target is associated with some cost that is increasing in the extent of the failure of fulfilment. ${ }^{9}$ Let $k_{i} \geqq 0$ denote the weight of commodity $i$ in the total demand (e.g., the carbon content per consumption unit of commodity $i$ ). Substituting the Marshallian total demand function for the $n$ commodities $X^{m}\left(q_{0}, \mathbf{q}, I\right) \equiv \sum_{i=1}^{n} k_{i} x_{i}^{m}\left(q_{0}, \mathbf{q}, I\right)$, into the cost function $D$ the maximisation problem of the government becomes ${ }^{10}$

\footnotetext{
9 The function $D$ reflects the case that the target level has to be reached from above (reduction of demand). More generally, to deal with the case that the target level has to be reached from below (increase of demand), we may redefine a cost (or damage) function by $D(|Y|)$ with $Y \in \mathbb{R}$.

10 A special case of this problem is where there is a strictly binding constraint on consumption (i.e., $\left.X^{m}\left(q_{0}, \mathbf{q}, I\right)=\bar{Z}\right)$, rather than a target on which the government may compromise.
} 


$$
\underset{\mathbf{q}}{\operatorname{Maximise}} V\left(q_{0}, \mathbf{q}, I\right)-D\left(X^{m}\left(q_{0}, \mathbf{q}, I\right)-\bar{Z}\right) .
$$

Subsequently, we use the following elasticities: We define the elasticity of Marshallian demand of commodity $i$ with respect to the price of commodity $j$ by $\varepsilon_{i j}^{m} \equiv\left(\partial x_{i}^{m} / \partial q_{j}\right)\left(q_{j} / x_{i}\right)$; and, the elasticity of Hicksian demand of commodity $i$ with respect to the price of commodity $j$ by $\varepsilon_{i j}^{h} \equiv\left(\partial x_{i}^{h} / \partial q_{j}\right)\left(q_{j} / x_{i}\right)$. In the following, we simply write $x_{j}$ and $X$ to denote the image of the demand functions under consideration.

\section{Results}

Using $\partial X^{m} / \partial q_{j}=\sum_{i=1}^{n} k_{i}\left(\partial x_{i}^{m} / \partial q_{j}\right)$, the first order conditions of problem (1) are ar $^{11}$

$$
\frac{\partial V}{\partial q_{j}}-D^{\prime} \frac{\partial X^{m}}{\partial q_{j}}=0, \quad j=1,2, \ldots, n,
$$

where $D^{\prime}$ represents the marginal cost of over-consumption; and accordingly, the term $D^{\prime} k_{i}$ represents the associated marginal cost of commodity $i$. Applying Roy's identity, we obtain

$$
-\mu x_{j}-D^{\prime} \frac{\partial X^{m}}{\partial q_{j}}=0, \quad j=1,2, \ldots, n,
$$

where $\mu \equiv \partial V / \partial I$ represents the marginal utility of income. Finally, using the Slutsky equation, we may express Eq. (2) as

$$
-\mu+D^{\prime} \frac{\partial X^{m}}{\partial I}=\frac{D^{\prime}}{x_{j}} \frac{\partial X^{h}}{\partial q_{j}}, \quad j=1,2, \ldots, n,
$$

where $X^{h}\left(q_{0}, \mathbf{q}, v\right) \equiv \sum_{i=1}^{n} k_{i} x_{i}^{h}\left(q_{0}, \mathbf{q}, v\right)$ is the Hicksian total demand function for the $n$ commodities.

Remark 1 Considering Eq. (2), we make the following observation: If we interpret the term $D^{\prime} k_{i}$ as the marginal damage of commodity $i$, and the government applies Pigouvian taxation, by setting tax rates equal to the marginal damage, i.e., $t_{i}=D^{\prime} k_{i}, i=1,2, \ldots, n$-though there is no rationale for such a behaviour in our model-then we obtain

$$
-\mu x_{j}-\sum_{i=1}^{n} t_{i} \frac{\partial x_{i}^{m}}{\partial q_{j}}=0, \quad j=1,2, \ldots, n,
$$

which has the same form as the first order equations in the optimal taxation problem with a revenue constraint [see, e.g., equation (12) in Sandmo 1974].

\footnotetext{
11 It can be shown that the second-order conditions are satisfied in suitably chosen examples (e.g., with a Cobb-Douglas utility function and with $\left.D(Y) \equiv Y^{a}, a>1\right)$.
} 
Let $\sigma_{j}^{m} \equiv\left(\partial X^{m} / \partial q_{j}\right)\left(q_{j} / X\right)$ denote the elasticity of Marshallian total demand with respect to the price of commodity $j$; and $v_{j} \equiv k_{j} x_{j} / X$, the demand share of commodity $j$. Also, let $\sigma_{j}^{h} \equiv\left(\partial X^{h} / \partial q_{j}\right)\left(q_{j} / X\right)$ denote the elasticity of Hicksian total demand with respect to the price of commodity $j$; and $\sigma_{I} \equiv\left(\partial X^{m} / \partial I\right)(I / X)$, the income elasticity of Marshallian total demand. Then, we obtain the following rule of optimal taxation under a quantity target.

Theorem 1 (Optimal taxation under a quantity target) For the taxation problem (1) the optimal consumer prices are (implicitly) given by

$$
q_{j}=-\frac{D^{\prime}}{\mu} \frac{\sigma_{j}^{m}}{v_{j}} k_{j}, \quad j=1,2, \ldots, n,
$$

or equivalently by

$$
q_{j}=-\frac{D^{\prime}}{\mu} \frac{\sigma_{j}^{h}}{v_{j}} \frac{k_{j}}{1-\sigma_{I} \frac{X}{I} \frac{D^{\prime}}{\mu}}, \quad j=1,2, \ldots, n
$$

Proof Multiplying both sides of Eq. (2) by $q_{j} / X$ and rearranging terms yields the first equality; and re-writing Eq. (3) yields the second equality.

Theorem 1 gives the rule of optimal taxation under a quantity target in terms of Marshallian and Hicksian demand functions, respectively; it implies that the solution of problem (1) is proportional to the price elasticity, $\sigma_{j}^{m}$ or $\sigma_{j}^{h}$, and to the cost weight $k_{j}$ (and thus to the marginal cost $D^{\prime} k_{j}$ ), but is inversely proportional to the consumption share $v_{j}$. That is, higher prices should be charged for commodities with high price elasticities and low consumption shares. This finding holds irrespective of whether we express the taxation rule in terms of Marshallian or Hicksian demand functions.

We next consider the special case where all cross price effects between the commodities are zero.

Corollary 1 (Anti-inverse elasticity result)

(i) Let $\partial x_{i}^{m} / \partial q_{j}=0(i, j=1,2, \ldots, n$ and $i \neq j)$. For the taxation problem (1) the optimal consumer prices are (implicitly) given by

$$
q_{j}=-\frac{D^{\prime}}{\mu} k_{j} \varepsilon_{j j}^{m}, \quad j=1,2, \ldots, n .
$$

(ii) Let $\partial x_{i}^{h} / \partial q_{j}=0(i, j=1,2, \ldots, n$ and $i \neq j)$. For the taxation problem (1) the optimal consumer prices are (implicitly) given by

$$
q_{j}=\frac{D^{\prime}}{\theta} k_{j} \varepsilon_{j j}^{h}, \quad j=1,2, \ldots, n,
$$

where $\theta \equiv-\mu+D^{\prime} \frac{\partial X^{m}}{\partial I}$, which is independent of $j$. 
Proof Using the fact that $\partial X^{m} / \partial q_{j}=\sum_{i=1}^{n} k_{i}\left(\partial x_{i}^{m} / \partial q_{j}\right), \forall j$, we obtain from Eq. (4) that the optimal consumer prices for the taxation problem (1) are (implicitly) given by

$$
q_{j}=-\frac{D^{\prime}}{\mu x_{j}} \sum_{i=1}^{n} k_{i} \varepsilon_{i j}^{m} x_{i}, \quad j=1,2, \ldots, n .
$$

Then the first equality immediately follows from Eq. (8). The second equality follows from Eq. (3): using the fact that $\partial X^{h} / \partial q_{j}=\sum_{i=1}^{h} k_{i}\left(\partial x_{i}^{h} / \partial q_{j}\right), \forall j$, yields

$$
\theta=D^{\prime} \sum_{i=1}^{n} \frac{k_{i}}{q_{i}} \varepsilon_{j i}^{h}, \quad j=1,2, \ldots, n .
$$

Then, using the assumption that $\partial x_{i}^{h} / \partial q_{j}=0(i, j=1,2, \ldots, n$ and $i \neq j)$, the result follows from the last equation.

According to Corollary 1, when either all compensated or all uncompensated cross price effects between commodities are zero, a quite simple taxation rule applies: higher prices should be charged for the commodities with the higher (own-) price elasticities and higher weights (and thus with higher marginal costs). Again, this rule holds irrespective of whether we express the result in terms of the elasticities of Marshallian or Hicksian demand functions. We thus found an anti-inverse elasticity result for both Marshallian and Hicksian demand. Moreover, since Eq. (8) represents the generalisation of Eq. (6), we may regard the former as a generalised anti-inverse elasticity result.

Corollary 2 (Anti-Corlett-Hague result) Let there be two commodities, i.e., $n=2$. For the taxation problem (1) the optimal consumer prices are (implicitly) given by

$$
\frac{q_{1}}{q_{2}}=\frac{k_{1}\left(\varepsilon_{21}^{h}+\varepsilon_{12}^{h}+\varepsilon_{10}^{h}\right)}{k_{2}\left(\varepsilon_{12}^{h}+\varepsilon_{21}^{h}+\varepsilon_{20}^{h}\right)} .
$$

Proof Using Eq. (9) for $j=1$, 2, eliminating $\theta$ and using Hicks' (1939) "third law" yields Eq. (10).

It follows from Eq. (10) that for $k_{1}=k_{2}$ we have: $q_{1} \gtrless q_{2} \Leftrightarrow \varepsilon_{10}^{h} \gtrless \varepsilon_{20}^{h}$, provided that the denominator and numerator of the right-hand side are positive. Accordingly, a higher consumer price should be charged for the commodity with the higher compensated price elasticity with respect to the composite good. We thus obtained an anti-Corlett-Hague result.

Also, we are able to establish a generalised uniform-pricing result:

Corollary 3 (Generalised uniform-pricing result) For the taxation problem (1) the optimal weighted consumer prices are all equal if, and only if, all commodities are equally weakly substitutable with respect to the untaxed composite good:

$$
\frac{q_{i}}{k_{i}}=r, \quad \forall i \neq 0 \Leftrightarrow \varepsilon_{i 0}^{h}=\alpha \geqq 0, \quad \forall i \neq 0 .
$$


Proof See Appendix for the proof of this result.

For example, in the case of $\mathrm{CO}_{2}$ emissions, the weighted consumer prices $q_{i} / k_{i}$ in Eq. (11) may be interpreted as prices in terms of the carbon contained in different types of fuel (cf. footnote 3); and the same interpretation applies to Theorem 1 and Corollaries 1 and 2 if we write Eqs. (4)-(7) and (10) in terms of the weighted consumer prices $q_{i} / k_{i}$. Finally, in the special case where the weights are all equal, i.e., $k_{i}=$ $k, \forall i \neq 0$, we obtain a strict version of our uniform-pricing result:

Corollary 4 (Uniform-pricing result) Assume $k_{i}=k, \forall i \neq 0$. Then, for the taxation problem (1) the optimal consumer prices are all equal if, and only if, all commodities are equally weakly substitutable with respect to the untaxed composite good:

$$
q_{i}=q \equiv r k, \quad \forall i \neq 0 \Leftrightarrow \varepsilon_{i 0}^{h}=\alpha \geqq 0, \quad \forall i \neq 0 .
$$

Proof This result follows immediately from Corollary 3.

The result of uniform taxation, presented, for example, by Diamond and Mirrlees (1971), Sandmo (1974), and Sadka (1977), is formally obtained under the same elasticity condition as is Corollary 3. ${ }^{12}$ However, in the basic optimal commodity tax problem with $n$ (or two) goods and leisure (good 0), Auerbach (1985, p. 90) and Auerbach and Hines (2002, p. 1368) interpret the case $\varepsilon_{i 0}^{h}=\alpha(\forall i \neq 0)$ as meaning that all goods are equally complementary to leisure. ${ }^{13}$ In this respect, Corollary 3 helps correct this interpretation, for it shows that the cross price elasticities cannot be negative (but must be non-negative), and hence the goods cannot be complementary to leisure.

The uniform-pricing result derived here and the familiar uniform taxation rule are both obtained under the same elasticity condition, but their implications generically differ: The uniform taxation rule is concerned with tax rates, i.e., $t_{j} / p_{j}$, while the uniform-pricing result with equal weights (i.e., $k_{i}=k, \forall i$ ) is concerned with consumer prices, $p_{j}+t_{j}$. Thus, the equal tax rates in the uniform taxation rule implies that higher specific taxes should be imposed on goods with higher net prices. Yet, the uniformpricing result, viz. equal consumer prices, implies that higher taxes should be imposed on commodities with lower net prices (provided that taxes are positive). In this sense, the uniform taxation rule and the uniform-pricing result are at variance with each other in general, and only coincide in the special case when all net prices are equal (i.e., $\left.p_{i}=p, \forall i \neq 0\right)$.

If all compensated cross price elasticities of the commodities with respect to the composite good are equal and non-negative, then we have the uniform-pricing result. On the other hand, if this equal elasticity condition does not hold, then we obtain

\footnotetext{
12 Sandmo (1974) also shows that this condition is satisfied when the utility function is weakly separable, written as $u\left(x_{0}, f(\mathbf{x})\right)$, and the function $f$ is homogeneous of some arbitrary positive degree. See also footnote 7.

13 Similarly, Heady (1993, p. 33) states that "all goods have the same degree of complementarity or substitutability with leisure"; Sørensen (2007, p. 387), that "goods and services are equally substitutable for (complementary to) leisure"; and Boadway (2012, p. 54), that "all goods must be equally complementary with leisure."
} 
the anti-inverse elasticity result and the anti-Corlett-Hague result. ${ }^{14}$ Hence, the policy implications of our problem depend on the values of the compensated price elasticities, and it is important to investigate the empirical validity of the equal elasticity condition.

For the standard optimal taxation problem under a revenue constraint, as mentioned in footnote 12 , this equal elasticity condition is satisfied when the consumer has weakly separable preferences (between the untaxed good, e.g., leisure, and the taxed goods) and the sub-utility function (of the taxed goods) is positive homogeneous. Although empirical studies frequently reject the hypothesis of weak separability (see, e.g., the references provided by Jacobs and Boadway 2014, footnote 2), uniform commodity taxation under weak separability is still a major issue in the contemporary literature, and the discussion has even been freshened and accelerated by the Mirrlees review (Mirrlees et al. 2011). ${ }^{15}$

In this paper, we consider a group of different commodities and their relations to some untaxed good. In the literature there is an ongoing discussion on this relation between close substitutes and some untaxed third good: For example, Borcherding and Silberberg (1978) and Silberberg and Suen (2001, p. 340) argue that two close substitutes such as a high and a low quality of the same good (e.g., apples) should be similarly related to other goods (a composite good) and the asymmetry in this relation seems to be "empirically insignificant." However, Minagawa (2012) questions this view, providing a conceptual qualification to this argument: suppose that there are three goods, say high and low priced (quality of) coffee beans, and milk. Then, a rise in the price of the high quality coffee leads to an exchange of one unit of this quality for more than one unit of the low quality coffee (due to the exchange rate). The total consumption of coffee beans thus increases, and correspondingly the total consumption of milk also increases provided that the consumer always takes their coffee with milk. In this case, the more expensive high-quality coffee beans and milk are substitutes while the less expensive low-quality coffee beans and milk are complements.

\section{Conclusion}

In this paper, we considered the problem of optimal commodity tax under a consumption target: the government chooses consumer prices (or unit taxes) for the different commodities of a specific group to maximise consumer welfare subject to the constraint that total consumption should meet a given target. To acknowledge the fact that governments frequently do not strictly adhere to the target they have or are committed to, we allow for some slackness in the achievement of the consumption target; yet, there are costs of failure associated with and increasing in the discrepancy between the consumption target and the actual level of consumption.

We demonstrated that the replacement of the familiar budget constraint by the consumption target leads to taxation rules that are predominantly at variance with

\footnotetext{
14 Notice that we may rewrite Eq. (7) as $q_{j}=-D^{\prime} k_{j} \varepsilon_{j 0}^{h} / \theta, j=1,2, \ldots, n$, by using the fact that $\varepsilon_{j 0}^{h}=-\varepsilon_{j j}^{h}, j=1,2, \ldots, n$.

15 The discussion on uniform commodity taxation in the Mirrlees review is based on Crawford et al. (2010), and it is further explored by Bastani et al. (2015) and others.
} 
their traditional counterparts. In particular, we showed that higher consumer prices should be charged for commodities with high price elasticities for the total demand and low consumption shares. We then obtained an anti-inverse elasticity result: higher consumer prices should be charged for commodities with a more elastic demand; and an anti-Corlett-Hague result: higher consumer prices should be charged for the commodity with the higher compensated price elasticity of the commodity with respect to an untaxed good. We also derived the uniform-pricing result, which is at variance with the familiar rule of uniform taxation (unless all net prices are equal): the same consumer price for all commodities should be charged if, and only if, the compensated price elasticities of the commodities with respect to the price of an untaxed good are all equal and non-negative. We thus conclude from our analysis that the implications for public tax policies crucially depend on (1) the type of the constraint-revenue constraint vs. consumption target - and on (2) the values of the price elasticities of the commodities with respect to an untaxed good. The choice of the specific constraint should thus be made very carefully, and the values of the price elasticities must be estimated with accuracy.

Acknowledgements We are grateful to Ben Lockwood and two anonymous referees for their helpful and inspiring comments.

\section{Appendix: Proof of the generalised uniform-pricing result}

We first prove the "only if." For equal weighted consumer prices, $q_{i} / k_{i}=r \forall i=$ $1, \ldots, n$, the right-hand side of Eq. (9) becomes $\left(D^{\prime} / r\right) \sum_{i=1}^{n} \varepsilon_{j i}^{h}$. Using Hicks' (1939) "third law," we get $\left(D^{\prime} / r\right) \sum_{i=1}^{n} \varepsilon_{j i}^{h}=\left(D^{\prime} / r\right)\left(-\varepsilon_{j 0}^{h}\right)$. Then, all $\varepsilon_{j 0}^{h}(j \neq 0)$ must be equal. This implies that all $\varepsilon_{i 0}^{h}$ and $\varepsilon_{0 i}^{h}(\forall i \neq 0)$ have the same sign, since $\partial x_{i}^{h} / \partial q_{j}=\partial x_{j}^{h} / \partial q_{i}$. Also, using Hicks' "third law" and the fact that $\varepsilon_{00}^{h} \leqq 0$, we obtain $\sum_{i=1}^{n} \varepsilon_{0 i}^{h}=-\varepsilon_{00}^{h} \geqq 0$. Therefore, all $\varepsilon_{0 i}^{h}$ and $\varepsilon_{i 0}^{h}(\forall i \neq 0)$ must be non-negative.

Next, we prove the "if." 16 Suppose that all commodities are equally weakly substitutable with respect to the composite good, $\varepsilon_{j 0}^{h}=\alpha \geqq 0, \forall j \neq 0$. Then, by definition, $\partial x_{j}^{h} / \partial q_{0}=\alpha x_{j} / q_{0}$. Thus, by symmetry, $\partial x_{0}^{h} / \partial q_{j}=\alpha x_{j} / q_{0}$. Substituting this relation into the Slutsky equation yields

$$
\frac{\partial x_{0}^{m}}{\partial q_{j}}=\frac{\partial x_{0}^{h}}{\partial q_{j}}-\frac{\partial x_{0}^{m}}{\partial I} x_{j}=\left(\alpha-\frac{\partial x_{0}^{m}}{\partial I} q_{0}\right) \frac{x_{j}}{q_{0}}, \quad j=1,2, \ldots, n .
$$

The term within the parentheses in Eq. (A-1) is independent of $j$, and we denote it by $\beta$, that is, $\partial x_{0}^{m} / \partial q_{j}=\beta x_{j} / q_{0}$. Now, differentiating both sides of the identity $\sum_{i=0}^{n} q_{i} x_{i}^{m}\left(q_{0}, \mathbf{q}, I\right) \equiv I$ with respect to $q_{j}$ and using the above relation, we obtain

\footnotetext{
16 This is similar to the demonstration of the uniformity of tax rates in the basic optimal commodity tax problem given by Sandmo (1974). See also Sadka (1977).
} 


$$
x_{j}=-\frac{1}{1+\beta} \sum_{i=1}^{n} q_{i} \frac{\partial x_{i}^{m}}{\partial q_{j}} .
$$

Substituting this into Eq. (2) yields

$$
\sum_{i=1}^{n}\left[\frac{\mu}{(1+\beta)} q_{i}-D^{\prime} k_{i}\right] \frac{\partial x_{i}^{m}}{\partial q_{j}}=0, \quad j=1,2, \ldots, n .
$$

Then, $[\mu /(1+\beta)] q_{i}-D^{\prime} k_{i}=0, \quad \forall i \neq 0$ is a solution of Eq. (A-3). ${ }^{17}$ That is, $q_{i} / k_{i}=(1+\beta) D^{\prime} / \mu, \forall i \neq 0$. The solution is independent of $i$ and may be denoted by $r$.

\section{References}

Auerbach AJ (1985) The theory of excess burden and optimal taxation. In: Auerbach AJ, Feldstein M (eds) Handbook of public economics, vol 1. North-Holland, Amsterdam, pp 61-127

Auerbach AJ, Hines JR Jr (2002) Taxation and economic efficiency. In: Auerbach AJ, Feldstein M (eds) Handbook of public economics, vol 3. Elsevier, Amsterdam, pp 1347-1421

Barbie M, Hermeling C (2009) The geometry of optimal taxation: a primal approach. Econ Theory 39(1):129-155

Bastani S, Blomquist S, Pirttilä J (2015) How should commodities be taxed? A counter-argument to the recommendation in the mirrlees review. Oxf Econ Pap 67(2):455-478

Besley T, Jewitt I (1995) Uniform taxation and consumer preferences. J Public Econ 58(1):73-84

Boadway R (2012) From optimal tax theory to tax policy. The MIT Press, Cambridge

Borcherding TE, Silberberg E (1978) Shipping the good apples out: the Alchian and Allen theorem reconsidered. J Polit Econ 86(1):131-138

Corlett WJ, Hague DC (1953) Complementarity and the excess burden of taxation. Rev Econ Stud 21(1):2130

Crawford I, Keen M, Smith S (2010) Value added tax and excises. In: Mirrlees J, Adam S, Besley T, Blundell R, Bond S, Chote R, Gammie M, Johnson P, Myles G, Poterba J (eds) Dimensions of tax design: the mirrlees review. Oxford University Press, Oxford

Deaton A (1979) The distance function in consumer behaviour with applications to index numbers and optimal taxation. Rev Econ Stud 46(3):391-405

Diamond PA, Mirrlees JA (1971) Optimal taxation and public production: I-II. American Economic Review. 61(1):8-27 [(3): 261-278]

European Commission (2009) Proposal for a council recommendation on seasonal influenza vaccination. https://ec.europa.eu/health/vaccination/key_documents_en

European Commission (2015) Excise duty tables, REF 1044. https://ec.europa.eu/taxation_customs/index_ en

Heady C (1993) Optimal taxation as a guide to tax policy: a survey. Fisc Stud 14(1):15-41

Hicks JR (1939) Value and capital. Clarendon Press, Oxford

Jacobs B, Boadway R (2014) Optimal linear commodity taxation under optimal non-linear income taxation. J Public Econ 117:201-210

Kaplow L (2010) Taxing leisure complements. Econ Inquiry 48(4):1065-1071

Kleven HJ, Richter WF, Sørensen PB (2000) Optimal taxation with household production. Oxf Econ Pap 52(3):584-594

Kopczuk W (2003) A note on optimal taxation in the presence of externalities. Econ Lett 80(1):81-86

Minagawa J (2012) On Giffen-like goods. Econ Lett 115(2):282-285

Mirrlees J, Adam S, Besley T, Blundell R, Bond S, Chote R, Gammie M, Johnson P, Myles G, Poterba J (eds) (2011) Tax by design: the Mirrlees review. Oxford University Press, Oxford

17 The solution is unique if the matrix $\left(\partial x_{i}^{m} / \partial q_{j}\right)(i, j=1,2, \ldots, n)$ is non-singular. 
Ramsey FP (1927) A contribution to the theory of taxation. Econ J 37(145):47-61

Sadka E (1977) A theorem on uniform taxation. J Public Econ 7(3):387-391

Sandmo A (1974) A note on the structure of optimal taxation. Am Econ Rev 64(4):701-706

Sandmo A (1975) Optimal taxation in the presence of externalities. Swed J Econ 77(1):86-98

Sandmo A (1987) A reinterpretation of elasticity formulae in optimum tax theory. Economica 54(213):89-96

Silberberg E, Suen W (2001) The structure of economics: a mathematical analysis, 3rd edn. McGraw-Hill, New York

Sørensen PB (2007) The theory of optimal taxation: what is the policy relevance? Int Tax Public Fin 14(4):383-406

Stiglitz JE (2015) In praise of Frank Ramsey's contribution to the theory of taxation. Econ J 125(583):235268

U.S. Environmental Protection Agency (2005) Emission facts. EPA420-F-05-001. https://www.epa.gov/ nscep

World Health Assembly (2003) Prevention and control of influenza pandemics and annual epidemics. WHA56.19, 28. http://apps.who.int/iris/handle/10665/78320

World Health Organisation (2003-2005) WHO framework convention on tobacco control. http://www.who. int/fctc/en/ 